\title{
Agentes comunitários de saúde: perfil e formação
}

\author{
Community health agents: profile and education
}

CarlaKowalski Marzari ${ }^{1}$ JoséRoque unges ${ }^{2}$

Lucilda Selli ${ }^{2}$
${ }^{1}$ FaculdadeIntegrada de Santa M aria. Ruajosédo Patrocínio 26, Centro. 97010-260 Santa M aria RS. carla.marzari@fisma.com.br

${ }^{2}$ Universidade do Vale do Rio dos Sinos.
Abstract This research discusses the profile and education of the community health agents. There is no clarity about the kind of professional needed and the appropriate training to the fulfillment of the function. The research is a case study with exploratory methodology and qualitative approach. The data was collected with a focused group, formed by ten agents, intentional selected from those with more time in service in Family $\mathrm{H}$ ealth Strategy teams from the municipality of Santa M aria, Rio Grande do Sul State. The discussions were recorded and transcribed by the re searcher. The data wasinterpreted by content analysis. The results pointed to some important questions concerning the identity of the community health agents: integration on the health team, insertion in the community, profile and education. The profile which emerges from the research, is not different from the one proposed by the M inistry of $\mathrm{H}$ ealth. However, the difference is the professionalization, an initiativeassumed by theagent, guided by reality, which he faces in his activity. The gaps, perceived in his formation, cause the agent to construct his professional identity, determined more by the technical aspect of the scientific knowledge than by his social competence as a community agent.

Key words Family health strategy, Community health agent, Health team, Community, Profile, Formation, Professionalize
Resumo A pesquisa discute o perfil ea formação dos agentes comunitários desaúde. Não existeainda clareza sobre o tipo de profissional necessário e a formação adequada para o desempenho da função. Trata-se deum estudo de caso com metodologia exploratória eabordagem qualitativa. A coleta de dados foi com grupo focal formado por dez agentes, selecionados intencionalmenteentreaque les com mais tempo de serviço nas Equipes da Estratégia Saúde da Família do município de Santa $M$ aria (RS). As discussões foram gravadas etranscritas. Os dados foram trabal hadosatravésda análise de conteúdo. Os resultados apontaram para algumas questões centrais sobre a identidade dos agentes: integração na equipe de saúde, inserção na comunidade, perfil e formação. 0 perfil que emerge da pesquisa não é diferente daquele proposto pelo M inistério da Saúde. No entanto, o diferencial é a busca por profissionalização, iniciativa assumida pel o próprio agente, efetivada epautada pela realidade que ele enfrenta a partir da sua atuação. Aslacunas percebidas na sua formação levam o agente a construir sua própria identidade profissional, pautada mais pelo aspecto técnico do conhecimento científico do que pela sua competência social como agente comunitário.

Palavras-chave Estratégia Saúde da Família, Agente comunitário de saúde, Equipe de saúde, Comunidade, Perfil, Formação, Profissionalizar 


\section{Introdução}

Os agentes comunitários de saúde (ACS) constituem uma importante estratégia de aprimoramento e de consolidação da Estratégia Saúde da Família (ESF), pois as principais ações deste programa se dão por meio dos ACS, pessoas escoIhidas dentro da comunidade para atuarem junto à população ${ }^{1}$.

O sucesso dessa estratégia depende do vínculo entre os profissionais da saúde e a população, ampliando a eficácia das ações de saúde nos usuários e favorecendo a participação da comunidade. Assim, a ESF propõe mudanças no objeto da atenção, na forma de atuação e na organização dos serviços em novas bases e critérios².

Dessa forma, a família passou a ser o foco da atenção em saúde, percebida a partir do seu ambientefísico e social, possibilitando às equipes de saúde uma compreensão ampliada do processo saúde/doença e da necessidade de intervenções para além das práticas curativas ${ }^{3}$.

o ACS desponta como o elo que possibilita a confiança e o vínculo entre a equipe de saúde ea comunidade assistida. Contudo, sua "formação" para o desempenho dessas funções precisa ser revista, considerando a amplitude do seu papel. A profissionalização dosACS deve ser concebida como um processo voltado para a realidade em que está inserido. Essa percepção do ambiente e da cultura local deve estar claramente presente no desempenho de suas funções. Esse olhar se fundamenta no fato de que a formação cultural influencia muitos aspectos da vida das pessoas, interferindo fortemente na saúde4.

A proposta de pesquisa sobre o ACS parte do entendimento de que seu perfil e sua formação precisam ser mais bem definidos e especificados. Esses profissionais devem estar comprometidos com sua real idade local ecapacitados para contribuírem na minimização dos fatores que respondem pelos indicadores sociossanitários, favorecendo o reconhecimento das condições devida da população, das suas necessidades e prioridades.

\section{Caminho metodológico}

A pesquisa é um estudo de caso, usando o método exploratório e a abordagem qualitativa. 0 objeto de investigação foram os agentes comunitários de saúde das equipes da ESF do município de Santa M aria (RS).

A amostra foi intencional, definida após anuência da Secretaria M unicipal deSaúde para con- sulta aos dados sobre os agentes. Foram selecionados dez agentes com maior tempo de atuação, alguns anteriores à implantação da ESF na vigência do PACS no município. Entraram agentes entre três e onze anos de experiência, todas do sexo feminino, cinco delas fizeram o curso detécnica em enfermagem enquanto eram agentes.

Para a coleta dos dados, foi usada a técnica de discussão focal em grupo. Foram organizados cinco encontros com a duração de uma hora e meia, tendo os seguintes temas: apresentação da proposta de pesquisa, o papel do agente, identificação de necessidades, reflexão e problematização sobre o perfil e a formação dos agentes. Foi constatado que todas as agentes do município já estavam muito articuladas entre si e, por isso, a discussão fluiu bem e havia bastante consenso entre elas quanto ao perfil e a formação. Asfalas foram gravadase, posteriormente, transcritas pela pesquisadora. Os dados foram tratados por meio de análise de conteúdo.

O projeto de pesquisa foi submetido e aprovado pelo comitê de Ética em Pesquisa da Universidade do Vale do Rio dos Sinos (UNISIN OS) com a Resolução n 033/2006.

\section{Resultados ediscussão}

Os dados coletados apontam para al gumas questões centrais sobre a identidade do ACS: integração na equipe, inserção na comunidade, perfil e formação do ACS.

\section{Integração do agente na equipe}

As falas dos sujeitos da pesquisa evidenciam que o trabalho em equipe exige conhecer como cada profissional conjuga sua atividade nos âmbitos individual e coletivo ecomo searticulam as ações desenvolvidas pelos diferentes profissionais. N uma equipe multiprofissional, essa articulação refere-seà relação entre distintos processos de trabalhos. A interseção de saberes não acontece de forma tranquila, caracterizando aspectos contraditórios, como se evidenciou a partir das falas das agentes participantes da pesquisa. Algumas percebem uma integração frágil, outras questionam o perfil dos profissionais da equipe, pois "quando tem alguma reunião émais para os médicos e enfermeiros" (ACS, 45 anos, nove anos de atuação), outros destacam harmonização e equidade: "posso contar com a equipe quetrabalho, lá todo mundo écol ega ese dá muito bem, não tem essa de ter formação ou não, todo 
mundo éigual" (ACS, 33 anos, três anos de experiência); "me sinto tão importante dentro da equipequetrabalho como qualquer outro profissional" (ACS, 36 anos, sete anos de agente).

Se, por um lado, a noção de equipe revela-se bastante legitimada nas falas das agentes, por outro, essa constatação aponta para a necessidade de um próximo passo: construir possibilidades efetivas de uma prática na qual usuário e população sejam partícipes do trabal ho em equipe e integrados no processo de construção de um projeto assistencial comum. Da mesma maneira, a equipe deixa-se al cançar pela comunidade, porque ela própria sente-se como comunidade, usuário, cidadão, na busca de condições de vida mais saudáveis e mais integradas $5^{5,6}$.

A contradição nas falas acima pode ser avaliadaem função daidentidadeem construção do agente, visto que esse profissional éincorporado a uma nova maneira de se pensar a saúde. Ao mesmo tempo em que pertencem a uma equipe, sesentem à margem do processo, o que é interpretado pelas agentes como deficiência na sua formação.

Isso não representaria problema se, para o atendimento das demandas da comunidade, a integração do agente com a equipenão fossefundamental, pois é da reciprocidade dos sujeitos envolvidos nas atividades que depende a resolutividade das ações que contemplam as necessidades da comunidade.

Nunes et al. ${ }^{7}$ destacam que o processo de integração "gera ansiedade quando o ACS compara o seu conhecimento com o de outros profissionais da equipe. Isso os conduz, por vezes, a uma insatisfação quanto à irregularidade ou insuficiência da educação que recebem".

Uma agente de quarenta anos com onze anos de atuação destaca que a comunidade exige uma atitude diferenciada. Isso preocupa porque, como ela aponta, "às vezes estou em casa almoçando e chega alguém para pedir que eu olhe um exame, então fico apavorada, sei quenão éminha função", mas, por outro lado, isso Ihe confere autonomia, pois "o ACS atingiu certo grau de autonomia que, muitas vezes, por questões burocráticas, dispensam o falar com outros profissionais" .

A autonomia destacada pela agente relaciona-se com a esfera de liberdade de julgamento e tomada de decisão frente às necessidades de saúdedos usuários. Essa fala evidencia o que Peduzzi ${ }^{8}$ indica como o grau de autoridade social e legal que um determinado profissional possui para avaliar e tomar decisões no desempenho de suas funções cotidianas, independentemente de questões técnicas estabelecidas.
As diferenças técnicas que existem dentro da equipe são características da ESF, não podendo ser vistas como empecilhosà integração do agente na equipe. Pelo contrário, as diferenças técnicas podem ser consideradas como um fator que amplia a possibilidadedeuniversalização do atendimento, pois cada membro da equipe multiprofissional pode analisar as situações do cotidiano de uma forma totalizante, apreendendo as diversas dimensões de uma dada situação. No caso específico do agente comunitário, isso se relaciona com o seu potencial em decodificar as necessidades da população, traduzindo-as para a equipe ou dando um encaminhamento adequado independente da equipe.

Existe consenso sobrea relação do agentecom a equipe, canal de comunicação entre a comunidade e os profissionais. Uma agente de 45 anos com nove anos de atuação evidencia que "a comunidadenos considera a porta deentrada no posto desaúde, porquetentamosfacilitar as coi sas para a população".

No aspecto formal elegal, 0 agente funciona como elo entre a comunidade e a equipe de saúde. Sua atividade une dois mundos distintos, 0 da equipe com seu conhecimento científico, e o da comunidade, com sua cultura e seus costumes. Por isso, a integração do ACS na equipe multiprofissional é importante, por que decodifica as necessidades da comunidade.

Por outro lado, existe a experiência subjetiva do agente-usuário, permeada de frustração e de solidariedade enquanto agente social, mantendo profunda relação de pertença com o meio em que atua e vive, pois as pessoas da sua realidade social são as mesmas das suas ações de cuidado. Essa concordância de universo físico, social epsicológico estimula o empenho de buscar o bemestar desejado para o outro, como se fosse para si mesmo, numa ampliação profunda das aspirações de satisfação das necessidades. Uma agente de 33 anos com três anos de experiência expressa um sentimento de reconhecimento por parte da comunidade: "algumas vezes, me sinto muito mais valorizada pela comunidade do que pela equipe".

Percebe-se que os agentes se entendem mais elo integrador da comunidade do que da equipe, em função de sua identificação com a comunidade. Isso significa que o perfil profissional deve ser construído mais pela sua relação com a comunidade, já que a boa interação na equipe de pende da conjugação entre a formação técnica e o envolvimento com a comunidade, quevai além do conhecimento científico. Estabelece-seum vín- 
culo de confiança, levando a comunidade a identificar no agente um profissional capaz de ouvir seus problemas. U ma agente de 34 anos com oito anos de atuação constata que "algumas famílias que já visitei fazem questão de primeiro falar comigo sobre seus problemas e dificuldades e depois falar com o médico ou a enfermeira do posto".

A interação entre agente e equipe pode não estar se efetivando por que não se definiu completamente o papel desse novo profissional dentro da equipe, ou se ampliaram as suas funções, sem ter trabalhado o perfil ea formação do agente comunitário de saúde, exigindo mais "convisão" do que supervisão da parte dos outros profissionais?.

\section{Inserção do agente na comunidade}

As falas sobre a inserção na comunidade denotam um trabalho de permanente construção, por que, embora 0 agente more no local de atuação, a relação que precisa estabelecer, en quanto profissional, é bem diversa daquela que desenvolve como morador. Tanto é assim que existem manifestações indicadoras do quanto sua percepção da comunidadenão alcança o todo, como se observa a agente de 36 anos com sete anos de experiência: "eu não sabia o quanto era difícil a minha comunidade. Demorei três anos para entrar dentro da casa de uma família. D urante este tempo, a dona da casa só me recebia no portão".

A dificuldadeem relação à comunidadesurge não porque 0 agente não seja capaz ou não se integre totalmente, mas devido ao desconhecimento do trabalho do agente por parte da comunidade. Muitas pessoas do local não sabem ou não compreendem qual o papel do agente, como destacou a agente de quarenta anos com onze anos de atuação: "no início foi muito difícil a integração e adaptação com a comunidade, porqueeles não sabiam o que era o ACS, pois entramos dentro de suas casas e fazemos várias perguntas e muitos demoram para entender o nosso papel na comunidade".

A manifestação dessa agente evidencia a resistência à atuação do ACS na comunidade. 0 fato de viver na comunidade e ser conhecido não garante ao agente a integração necessária para desenvolver o trabalho. Para ela, é necessário envolvimento: "para ser ACS, precisamos participar e estar envolvidos com a comunidade".

0 envolvimento configura-se como problemático, por que o agente não está preparado para decodificar as demandas da comunidade, como afirma a agente de 34 anos com oito anos de experiên- cia: "alguns não têm perfil para atuar com a comunidade" .

A questão da integração na comunidade configura-se como fundamental, a partir do momento em quese resgata a definição de agentedo M inistério da Saúde: [...] um elo cultural do SU S com a população, fortalecendo 0 trabalho educativo e seu contato permanente com as famílias, facilitando o trabalho de vigilância e promoção da saúde. Sua inserção na comunidade permite que traduza para as USF a dinâmica social da população assistida, suas necessidades, potencialidades e limites, bem como identifique parceiros e recursos existentes que possam ser potencializados pelas equipes $[\ldots]^{10}$.

0 papel social do ACS junto à população sel egitima pelo grau de integração com a comunidade. 0 processo de adaptação à comunidade, muitas vezes, é lento, e a falta de preparação para atuar com a população é um fator de dificuldade, como constata a agente de 48 anos e oito anos de experiência: "ainda não sei como trabalhar com os vaIores das famílias". Os agentes participam inevitavelmente de problemas mais íntimos de pessoas da comunidade, difíceis de administrar, por que há um envolvimento profissional e também pessoal nessasquestões.

Com a ampliação da ESF no Brasil, os agentes de saúde assumiram responsabilidades como agentes transformadores, conferindo complexidade ao trabalho, por exigir uma síntese entre a dimensão social e humanitária com o saber prático da saúde ${ }^{11}$.

Percebe-se que o desafio de preparar profissionais adequados às necessidades do SUS implica, entre outras coisas, profundas alterações na organização da formação desses profissionais. Surge uma nova prática, pedindo reflexão sobre as competências exigidas para traçar o perfil profissional ${ }^{12}$.

\section{Perfil e profissionalização}

É possível imaginar dois perfis de agentes com seu respectivo processo formação. Um primeiro tipo seria um promotor de conscientização, mobilização e organização social da comunidade, assemelhando-se sua formação à dos assistentes sociais. Isso aparecenas falas da agente de 45 anos e nove anos de atuação: "o ACS é um líder comunitário; para se integrar com a comunidade tem que ser um facilitador" e em outra de 34 anos com oito anos de agente: "as famílias procuram a gente para solucionar seus problemas, oferecer algum tipo de atendimento ou encami- 
nhamento, ou só para desabafarem sobre algum problema queestão passando".

Essas afirmaações denotam um poder exercido pelo ACS em sua comunidade. Nessa perspectiva, 0 agente estaria capacitado para discutir a relação entre os fatores político-sociais mais abrangentes do processo saúde/doença. 0 êxito do seu trabal ho estaria no maior grau de organização e consequente reivindicação de melhorias para a saúde da comunidade. Esse perfil propicia que 0 agente organize grupos para lutar pelos direitos da comunidade.

O segundo tipo seria mais um agente sanitário com formação técnica em harmonia com as outras categorias profissionais. 0 êxito do seu trabalho estaria nos atendimentos e no eventual efeito sobre os padrões de morbimortalidade. Trabal haria nas respostas às necessidades individuais de saúde a partir de objetivos definidos pela unidade.

Para Tomas ${ }^{13}$, não existe uma clara delimitação das atribuições e do papel do ACS. Nos documento $\mathrm{s}^{14}$, está definido, mas falta esclarecimento legal pelo fato de que a profissão de agente caracteriza-secomo exercício deatividade deprevenção de doenças e promoção da saúde, mediante ações domiciliares ou comunitárias, individuais ou coletivas, desenvolvidas em conformidade com as diretrizes do SUS.

Não ocorre um trabalho sistemático de atualização desses profissionais para que possam atender às exigências da ESF, como assevera a agente de 36 anos com sete anos de experiência: "desde 2004 não há evento de capacitação para os ACS pela SM S". Fato confirmado por outra de 34 anos e oito anos de agente: "sem pre houve educação continuada, agora desde 2004 não ocorrem eventos deste ti po", eainda outra de 33 anos e três anos de agente: "os últimos ACS não receberam a capacitação que deveriam e estão despreparados".

0 desafio de preparar profissionais adequados às necessidades do SUS implica profundas alterações na organização da sua formação. A busca de programas alternativos de ensino mais adequados aos desenhos de organização da atenção primária precisa incorporar o conceito de competências, passando, necessariamente, pela vinculação entre educação e trabal ho.

A qualificação é um ponto de preocupação dos agentes, evidenciada na fala da agente de 33 anos com três anos de atuação: "o que nos falta é embasamento teórico para informar a população". A necessidade de profissionalização é unânime. Prova disso éque a metade do grupo possui curso técnico de enfermagem ou está cursando, motivada pela qualificação. A agente de 36 anose sete anos deexperiência afirma: "a busca por maioresconhecimentos dentro da nossa profissão éuma busca individual, pois não é oferecido nenhum curso de atualização".

A profissionalização do ACS é importante para as equipes e para a comunidade. No entanto, ela deve estar pautada pela realidade de cada comunidade e envolver toda a equipe de saúde, pois existem profissionais que ainda não entendem o papel do ACS.

Contudo, deve-se ressaltar, neste momento, que a profissionalização não necessariamente deve passar por cursos técnicos de enfermagem, pois os agentes têm um perfil de liderança social por sua capacidade de mobilizar a comunidade. Por isso, pode-se questionar a busca de cursos técnicos a partir de dois aspectos.

As agentes buscam um conhecimento técnico, por que querem igualar-se profissionalmente aos outros membros da equipe e, por falta de consciência sobreseu papel na comunidade, pensam que não se legitimam apenas pelo conhecimento cultural das peculiaridades da comunidade. Se para o desempenho de suas tarefas é importante o conhecimento popular, a busca de formação não necessariamente passaria pelos cursos técnicos de enfermagem, mas pela sua capacitação para o papel social ${ }^{15,16}$.

D evido aos seus aspectos políticos, a atuação do ACS independe de formação técnica em saúde. Os problemas de saúde enfrentados por de terminada comunidade não estão tanto na falta de acesso à unidade de saúde ou na falta de profissionais capacitados, mas nas questões ambientais do seu meio. A falta de saneamento não se resolve com ações profissionais, mas exige um agente social para mobilizar a comunidade.

A questão da profissionalização do ACS envolve complexidade, pois o seu trabalho éna comunidade, mais especificamente dentro dos domicílios. Por isso, Tomas ${ }^{13}$, quando propõe trabal har competências, enten de que 0 agente deve ter uma noção de causa, consequência e prevenção. As competências que o autor aponta são: observação, ética, noção de causa e consequência, comunicação, integração, liderança, responsabilidade e autonomia.

O perfil profissional do ACS converge para competências voltadas para a comunidadee para a equipe. As agentes foram unânimes em relatar que o perfil exige liderança, dinamismo, visão, responsabilidade, ética, força de vontade e doação. Esses elementos são enfatizados por que as agentes pensam ser necessário deixar-se envol- 
ver pela profissão. A agente de 36 anos com sete anos de atuação fala com convicção: "um ACS que não se enquadra nestes itens, ele não será um bom profissional ou não irá conseguir ficar muito tempo na profissãa".

Essa dimensão enfatizada pelos ACS indica sua percepção de que o trabalho é abrangente e requer sensibilidade. As agentes pensam ser necessário conjugar sensibilidade com exigências teóricas, comprovado pela busca de curso técnico de enfermagem. A agente de 35 anos e sete anos de experiência afirma: "minha casa vira extensão da comunidade, então as pessoas procuram esse atendimento individualizado e por quem elas confiam que somos nós. Elas sabem que não temos formação espeć́fica para isso, mas passamos confiança e amizade".

A percepção desses dois aspectos está relacionada com o que Silva e Dalmaso ${ }^{17,18}$ indicam sobre as duas exigências importantes para o desenvolvimento das atividades de ACS: uma teórica e outra mais abrangente, relacionada ao campo da sensibilidade. A fala da última agente indica uma relação de confiança e amizade, fomentadas por aspectos humanos que independem da formação profissional. Ela ressalta: "muitas vezes temos que lidar com os valores das pessoas, e como fazer isso?".

A perfeita conjugação entreessas duas dimensões requer atenção redobrada do profissional e dos órgãos responsáveis pela formação e profissionalização. Os ACS compreendem que o trabalho cotidiano exige constante atualização. Por isso, necessitam de cursos de formação continuada, ofertados pelas Secretarias de Saúde. Contudo, essa formação e educação permanente não podem acontecer de forma isolada e descontextualizada. Desde a implantação da ESF, percebem-se dificuldades em definir o tipo de formação necessária para os ACS, demasiadamente pensada a partir da atenção hospitalar e centrada na doença, esquecendo-se da sua contextualização com o trabalho cotidiano, em que se vivenciam as reais situações das comunidades.

0 interessepela busca deconhecimento évisível nas falas das agentes, pois a maioria fez ou está fazendo algum curso de aperfeiçoamento e atualização na área da saúde. A agente de 45 anos com nove anos de atuação conta: "trabalho o dia inteiro como ACS, à noite frequento um curso de pós-técnico, em uma instituição particular da cidade. Sinto necessidadeem aprender maissobresaúde e outros temas que convivemos no dia a dia". Esse depoimento indica que a agente sente certas deficiências frente às demandas da comunidadee está preocupada com a construção de uma atuação pautada pela integralidade. No entanto, procura isso numa pura formação técnica, denotando contradição com aquilo que é característico do agente, o saber popular em saúde e o conhecimento da dinâmica social da comunidade.

Segundo Nunes et al. ${ }^{7}$, os agentes, por fazerem parte da equipe de saúde, são levados a identificar-se com certos conteúdos e práticas referentes à biomedicina. Pelo tipo deformação recebida adquirem maior acesso ao saber biomédiCo, mais valorizado do que o conhecimento popular, conferindo-Ihes maior prestígio social. A busca de formação técnica confirma essa visão ilusória de que com conhecimentos biomédicos estariam mais capacitados para resolver os problemas da comunidade.

A profissionalização dos ACS não pode pretender exercer o papel dos outros profissionais de saúde. Como pessoas do povo, assemelhamse às características e aos anseios do povo, preenchendo as lacunas da equipe por conhecerem as necessidades daquela população. É necessário conscientizar o ACS para o valor do seu conhecimento genuíno adquirido pela pertença à sua comunidade. 0 perfil adequado envolver reflexão, sensibilidade, compromisso ereconhecimento de si mesmo como construtor de conhecimento, capaz de produzir um saber/fazer sobreas necessidades reais daquela comunidade.

\section{Considerações finais}

No contexto das mudanças nas práticas de saúde e na mobilização social e integração entre a população e as equipes de saúde, a importância do agente está na sua singularidade profissional, que transita entre a assistência social, a educação, a saúde e o meio ambiente.

0 perfil que emerge da pesquisa não é diferente daquele proposto pelo M inistério da Saúde. No entanto, o diferencial se dá na busca pela profissionalização, procurada pelo próprio agente e realizada de forma efetiva a partir da sua atuação. As lacunas percebidas na sua formação levam o agente a construir sua própria identidadeprofissional, independentemente de incentivo ou cobranças por parte de órgãos responsáveis pela sua capacitação.

No entanto, a busca pela formação pauta-se pelo conhecimento científico, como se o seu conhecimento empírico não tivesse importância. Deve-se enfatizar que esse conhecimento popular étão importante quanto aquel eque ele alme- 
ja adquirir numa sala de aula. Essa visão depende do seu autoconceito, pois, nos documentos oficiais, 0 agente é reconhecido pela pertença a uma comunidade e pelo seu saber popular. A proposta da ESF ainda não amadureceu suficientemente as questões referentes à uma lógica de trabalho em equipe que reconheça o perfil eestimule a formação específica do ACS.

\section{Colaboradores}

CK M arzari, JR Junges e L Selli colaboraram na concepção, metodologia, interpretação dos dados e redação final do artigo. CK M arzari realizou a coleta e a organização dos dados.

\section{Referências}

1. Brasil. Programa Saúde da Família: ampliando a cobertura para consolidar a mudança do modelo de atenção básica. Brasília: Ministério da Saúde; 2003.

2. Brasil. Ministério da Saúde. Saúde da família: uma estratégia para reorientação do modelo assistencial. Brasília: Ministério da Saúde; 1998.

3. Brasil. Ministério da Saúde. Programa Saúde da Família. Brasília: Ministério da Saúde; 1999.

4. Helman CG. Cultura, saúde e doença. 4a ed. Porto Alegre: Artmed; 2006.

5. Crevelim M A, Peduzzi M. A participação da comunidade na equipe de saúde da família. Como estabe lecer um projeto comum entre trabalhadores e usuários? Cien Saude Colet 2005; 10(2):323-331.

6. Ciampone MHT, Peduzzi M. Trabalho em equipe e trabalho em grupo no Programa de Saúde da Família. Rev. Bras. Enferm. 2000; 53(n. esp.):143-147.

7. Nunes MO, Trad LB, Almeida BA, Homem CR, M elo MCIC. O agente comunitário de saúde: construção da identidade desse personagem híbrido e polifônico. Cad Saude Publica 2002; 18(6):1639-1646.

8. Peduzzi M. Equipe multiprofissional de Saúde: conceito e tipologia. Rev. Saude Publica 2001; 35(1):103-109.

9. Hortale VA, Reis CCL. Programa de saúde família: supervisão ou convisão? Estudo de caso em município de médio porte. Cad Saude Publica 2004; 20(2):225-240.

10. Brasil. Ministério da Saúde. Curso de Formação de Facilitadores de Educação Permanente em Saúde. Brasília: Ministério da Saúde; 2005.

11. M endonça MHM. Resenha sobre o livro Agente Comunitário de Saúde: 0 ser, o saber e o fazer de Joana Azevedo Silva e Ana S. Whitaker Dalmaso. Cad Saude Publica 2004; 20(5):1433-1434.

12. Conasems. Agentes Comunitários de Saúde. Publicação do - Conselho Nacional dos Secretários Municipais de Saúde. [site da Internet] [acessado 2006 mai 24]. Disponível em: http://www.conasems.org.br 
13. Tomas JBC. O Agente Comunitário de Saúde não deve ser um "Super Herói". Interface (Botucatu) 2002; 6(10):75-94.

14. Brasil. Ministério da Saúde. Perfil de competências profissionais do Agente Comunitário de Saúde. Proposta relacionada à qualificação profissional básica do ACS [site da Internet] 2003 [acessado 2007 ago]. Disponível em: http://www.saserj.org.br/propostaacs.htm

15. Nogueira RP. $O$ trabalho do ACS entre a dimensão técnica "universalista" e a dimensão social "comunitarista". Interface (Botucatu) 2002; 6(10):75-94.

16. Nogueira RP, Silva F, Ramos Z. A vinculação institucional de um trabalhador sui generis - 0 agente comunitário de saúde. Textos para discussão n 735. [site da Internet] [acessado 2006 mai 24]. Disponível em: http://www.ipea.gov.br

17. Silva JA, Dalmaso ASW. O agente comunitário de saúde e suas atribuições: os desafios para os processos de formação de recursos humanos em saúde. Interface (Botucatu) 2002; 6(10):75-83.

18. Silva JA, Dalmaso ASW. Agente comunitário de saúde: 0 ser, o saber, o fazer. Rio de Janeiro: Fiocruz; 2002.

Artigo apresentado em 12/07/2008

Aprovado em 15/01/2009

Versão final apresentada em 15/02/2009 